\title{
Research
}

\section{Evidence-based Nursing Practice: How to Get There from Here}

\author{
Alba DiCenso, RN, PhD \\ Professor, Nursing and Clinical Epidemiology and Biostatistics \\ Director, Ontario Training Centre in Health Services and Policy Research \\ CHSRF/CIHR Nursing Chair in Advanced Practice Nursing \\ McMaster University, Hamilton, ON \\ Past Lead Editor, Evidence-Based Nursing Journal
}

As a nursing student, I learned to shave patients in preparation for surgery; as a public health nurse, I taught mothers to clean their infants' umbilical cords with alcohol and showed patients newly diagnosed with diabetes how to wipe the skin with alcohol before injecting insulin. Since then, high-quality research has shown that pre-operative shaving increases rather than decreases post-operative infections (Kjonniksen et al. 2002), that cleaning umbilical cords with sterile water shortens the time to cord separation without increasing infections (Medves and O'Brien 1997) and that insulin can be safely injected through clothing (Fleming et al. 1997). These are only three of innumerable examples of how high-quality studies of nursing care can influence our practice. And while it is heartening to know that new evidence is constantly emerging to inform our nursing practice, it is disheartening to learn that many nurses continue to rely on the increasingly dated knowledge they acquired as nursing students (Estabrooks 1998).

In this paper, I will describe how high-quality evidence fits into clinical decision-making in nursing practice, and I will call upon key professional groups, such as associations of nursing educators, executive nurses and national nursing organizations, to combine forces and create blue ribbon panels or task forces charged with making recommendations for changes in nursing education and practice that will advance us towards full development as an evidence-based profession.

\section{Evidence and Clinical Decision-making}

"Best research evidence" refers to methodologically sound, clinically relevant research about the effectiveness 
and safety of nursing interventions, the accuracy and precision of nursing assessment measures, the power of prognostic indicators, the strength of causal relationships, the cost-effectiveness of nursing interventions and the meaning of illness or patient experiences. Research evidence alone, however, is never sufficient to make a clinical decision. As nurses, we must always trade the benefits and risks, inconvenience and costs associated with alternative management strategies, and in doing so consider the patient's values (DiCenso et al. 1998). Patient values and preferences refer to the underlying assumptions and beliefs that are involved when we, along with patients, weigh what they will gain - or lose when we make a management decision. The explicit enumeration and balancing of benefits and risks that are central to evidence-based nursing (EBN) bring into bold relief the underlying value judgments involved in making management decisions.

The skills necessary to provide an evidence-based solution to a clinical dilemma include defining the problem; conducting an efficient search to locate the best evidence; critically appraising the evidence; and considering that evidence and its implications in the context of patients' circumstances and values. Attaining these skills requires intensive study and frequent, time-consuming application (Guyatt et al. 2000).

The majority of nurses have a positive attitude about evidence-based practice (Upton 1999). However, there are substantial barriers to EBN at both the individual and organizational levels.
At the individual level, nurses lack skill in evaluating the quality of research (Parahoo 2000), are isolated from knowledgeable colleagues with whom to discuss research (Nilsson Kajermo et al. 1998) and lack confidence to implement change (Parahoo 2000).

Organizational characteristics of healthcare settings are overwhelmingly the most significant barriers to research use among nurses (Parahoo 2000). Nurses speak about not having enough time to go to the library to read or to implement findings from research (Upton 1999). Related to this complaint is the inadequacy of library holdings in healthcare institutions, with many lacking nursing research journals (Mitchell et al. 1995). Nurses have identified a lack of organizational support for EBN, noting lack of interest, lack of motivation, lack of leadership and lack of vision, strategy and direction among managers (Parahoo 2000). Yet, this organizational support is crucial in situations where nurses do not believe they have the authority or autonomy to implement change in patient care (Parahoo 2000). For example, a physician may read about the effectiveness of a new pain medication and may choose to begin prescribing it immediately; nurses who identify a new, effective nursing intervention for pain management must often obtain approval from nursing administration before implementing it.

Clinicians and patients recognize that while not the sole consideration, current, accurate information is a vital component of clinical decision-making. With advances in information technol- 
ogy and reporting of research findings in the media, patients, armed with "facts" they have read on the Internet or in the newspaper, are beginning to ask their care providers about the applicability of research findings to their particular health problem. A vivid example is the widely publicized study of the risks and benefits of estrogen and progestin in post-menopausal women that was stopped early because the investigators found a higher incidence of cardiovascular disease and breast cancer in women taking the combined hormones when compared to women taking placebo (Writing Group for the Women's Health Initiative Investigators 2002). Physicians and nurse practitioners have been deluged with patient inquiries about whether they should discontinue their hormone replacement therapy, requiring these clinicians to be sufficiently aware of the study methods to judge the validity of the results and their applicability to individual patients.

Grounding nursing practice in evidence, rather than tradition, is necessary to meet nursing's social obligation of accountability, to gain and maintain credibility among other health disciplines and to build a nursing knowledge base that can be used to influence policy at agency and governmental levels (Rafael 2000). Governments around the world are encouraging evidence-based practice. In Canada, the National Health Forum, a federally funded group charged with making healthcare recommendations, has stated that "a key objective for the health sector should be to move rapidly toward the development of an evidence-based health system, in which decisions are made by healthcare providers, administrators, policy-makers, patients and the public on the bases of appropriate, balanced and high quality evidence" (National Forum on Health 1997). In the United Kingdom, the Department of Health has stipulated that, to enhance the quality of patient care, nursing, midwifery and health visiting, practice needs to be evidence based (UK Department of Health 1999).

In the United States, the Agency for Healthcare Research and Quality (AHRQ), formerly the Agency for Health Care Policy and Research (AHCPR), leads national efforts in the use of evidence to guide healthcare decisions through funding of EvidenceBased Practice Centers that undertake systematic reviews on selected clinical topics, sponsoring a National Guideline Clearinghouse of abstracts of evidencebased practice guidelines (www.guideline.gov) and funding studies that evaluate strategies for effectively disseminating research findings to practitioners and policy makers (Titler 2002). In December 2002, the Board of Directors of the Sigma Theta Tau International Honor Society of Nursing adopted a position statement supporting the development and implementation of EBN and committing itself to working closely with key partners to provide nurses with the most current and comprehensive resources to translate the best evidence into the best nursing research, education, administration, policy and practice (Honor Society of Nursing 2002). 


\section{Towards Full Development as an Evidence-based Profession}

Various activities have been initiated to facilitate EBN practice, including the development and offering of undergraduate courses on locating and critically appraising research evidence (Kessenich et al. 1997), the development of clinical practice guidelines (Grinspun et al. 2002), the development of EBN committees in clinical settings and research to identify the most effective strategies for disseminating research findings to nurses. But there is a long way to go. How do we create a culture shift that ensures that a nursing student knows how to search the literature for high-quality studies as proficiently as she can measure a patient's blood pressure, and that a staff nurse has access to the best research evidence to incorporate into clinical decision-making?

Let's begin by considering changes to nursing education programs. A number of ideas come to mind related to curriculum development, faculty development, librarian resources and accreditation criteria. Rather than isolating the teaching of critical appraisal of research in its own undergraduate course, can we re-examine our nursing curricula and consider how critical appraisal of research can be integrated into each and every learning experience, whether learning of clinical skills such as taking blood pressure, or in-class nursing courses, or clinical experiences in healthcare settings? Can we see a world where students in classrooms or in clinical settings go off to learn about a specific patient or health problem and return with a clearly stated question, the search strategy they used and the strengths and limitations of the highestquality study they found on the topic? If this were the approach to every course students took and every clinical experience they had, would consideration of best research evidence in their clinical decision-making become second nature for these future nurses? Clearly, none of this will happen if nursing faculty are not comfortable with critical appraisal skills.

To be fair, the opportunities to develop these skills have been relatively scarce. There is much to be done in this area. Various models can be explored for faculty development; for example, at McMaster University, an interdisciplinary, week-long, intense workshop on How to Teach Evidence-based Clinical Practice is conducted every June that attracts clinician educators from around the world. To ensure that nurse educators of the future are prepared to teach in an EBN curriculum, it is vitally important that the graduate nursing programs include required courses on critical appraisal and application of research evidence.

Librarians are an indispensable resource to evidence-based practice. In a number of undergraduate and graduate nursing courses at McMaster University, a health sciences librarian has set up course-specific Web Sites providing ready access to numerous sources of evidence-based material. As well, she spends a half day with the students in the computer laboratory providing hands-on experience in efficient advanced searching strategies to locate high-quality research evidence and to 
link with resources that can automatically notify the student when new studies are published in a specific area of interest. She is also available to meet individually with students.

These ideas, while promising, cannot be implemented without the buy-in and support of the deans and directors of schools and faculties of nursing. These are not resource-free ideas; instead, they are ideas that likely require financial and human resources as well as a supportive environment for change. Incorporation into the accreditation process of specific objectives and recommendations for transforming nursing education programs into evidence-based education programs are key to helping deans and directors obtain assistance with required resources from the university or college administration.

In clinical settings, let's consider computer and librarian resources, development and introduction of the nurse educator/practitioner/researcher role, journal clubs, interdisciplinary rounds and accreditation. Asking nurses to practise nursing without the tools to locate best evidence to inform their clinical decision-making is comparable to asking them to take a blood pressure measurement without a stethoscope. Many nurses, while highly motivated to become evidence-based practitioners, have not had any opportunity in their nursing education to learn searching and critical appraisal skills. To complicate matters further, time is more limited than ever.

There exist, however, numerous secondary sources of pre-appraised evidence that provide immediately applicable information for decisionmaking. Administrators of clinical settings can make a significant contribution to the development of evidencebased practice by providing access to these resources, along with opportunity for nurses to learn how to track down and efficiently use them. Such resources, which apply a methodological filter to original investigations and therefore ensure a minimum standard of validity, include Clinical Evidence, The Cochrane Library, Evidence-Based Nursing (and other discipline-specific abstraction journals, such as Evidence-Based Mental Health), high-quality clinical practice guidelines and an increasing number of computerized decision-support systems. Ready access to computers in the clinical setting and librarians is key. At a minimum, librarians can teach nurses how to frame an answerable question and how to use the secondary sources of pre-appraised evidence efficiently. The librarian becomes, in effect, a knowledge broker who is expert in sources of high-quality information and in teaching others how to access them efficiently.

For the most part, nursing educators are not active clinicians, and nurse clinicians are not nursing educators. At Rush University College of Nursing, they have developed the nurse educator/practitioner/researcher role in which faculty members have an ongoing research involvement and clinical practice alongside their responsibilities as educators, lecturers and advisers ("Inside the Rush Model” 2003). Picture clinical settings in which the nurse educator/practitioner/ researcher works closely with nursing 
staff to produce and disseminate new knowledge and, as an advanced practice nurse, models and facilitates evidence-based practice.

Should we consider bringing together, in the clinical setting, the nurse educator, the students and the nurse clinicians in the form of a journal club? Together, they can identify a patient problem; volunteers can then offer to search out the best evidence and bring it back for presentation and discussion with the group. This might provide a forum for learning from one another while at the same time helping nurses in the clinical setting, who lack time and critical appraisal skills.

There is an increasing awareness of the importance of interdisciplinary learning to facilitate the effective working of the multidisciplinary healthcare team in service delivery. We are beginning to see how challenging it is to promote interdisciplinary service when learning has occurred in unidisciplinary silos. Is there an opportunity in the clinical setting to bring together students from programs such as nursing, midwifery, medicine, occupational therapy and physiotherapy to consider a common patient problem and to search out and discuss relevant research findings? For example, at McMaster University, a multidisciplinary team has been awarded funds from the provincial government to develop models for collaborative education and collaborative service delivery in long-term care, including family medicine residents, w w w . k g h . ० n . c a

\section{A Thousand Ways to Enjoy Life!}

KINGSTON GENERAL HOSPITAL serves a population of 500,000 in Southeastern Ontario. Situated in Kingston, Ontario, we are mid-way between Toronto and Montreal at the gateway to the St. Lawrence River and the 1000 Islands. History, culture, recreation, entertainment, and a rich academic community combine to make Kingston a showcase for quality living . .

\section{Registered \& Advanced Practice Nurses}

Nurses work in a modern, rewarding, and meaningful environment where personal development and participation in constructive change are encouraged and supported. They are treated with respect and are expected to be involved in decision making processes. For a thousand ways to enjoy life and work, come to Kingston! Please contact: Human Resources Consultant, Human Resources Services, KINGSTON GENERAL HOSPITAL

Phone: (613) 549-6666 ext.2365

e-mail: kghhr@kgh.kari.net

\section{KCH GENERAL HOSPITAL}

A National Historic Site.

nurse practitioner students and pharmacy students. It is envisioned that both models will include the opportunity for these interdisciplinary learners and clinicians to work together through patient problems, identifying and using best evidence in their clinical decisionmaking.

Very little of this is possible without the support and provision of resources by the administrators of healthcare settings. Nurse managers may want to consider lobbying for inclusion of standards related to EBN practice in the accreditation mechanisms for their clinical settings. This action would appropriately highlight the importance of evidence-based practice and would ensure that essential resources be allocated to its development. 
The ideas offered above are merely suggestions. The development of an evidence-based profession is an extremely important initiative in nursing, one that warrants national attention and collaboration. I encourage key nursing groups, including associations of nursing educators, executive nurses and national nursing organizations, to combine forces and create blue ribbon panels or task forces charged with making recommendations for changes in nursing education and practice that will move us rapidly towards full development as an evidence-based profession.

Enthusiasm for evidence-based practice is growing in the nursing community. We must now develop, implement and evaluate a plan to make it happen.

\section{References}

DiCenso, A., N. Cullum and D. Ciliska. 1998. "Implementing Evidence-based Nursing: Some Misconceptions." Evidence-Based Nursing 1(2): $38-40$.

Estabrooks, C.A. 1998. "Will Evidence-based Nursing Practice Make Practice Perfect?" Canadian Journal of Nursing Research 30: 15-36.

Fleming, D.R., S.J. Jacober, M.A. Vandenberg et al. 1997. "The Safety of Injecting Insulin Through Clothing." Diabetes Care 20: 244-47.

Grinspun, D., T. Viraniand and I. Bajnok. 2002. "Nursing Best Practice Guidelines. The RNAO Project." Hospital Quarterly 5: 56-60.

Guyatt, G.H., M.O. Meade, R.Z. Jaeschke, D.J. Cook and R.B. Haynes. 2000. "Practitioners of Evidence-based Care.” British Medical Journal 320: 954-55.

Honor Society of Nursing, Sigma Theta Tau International, STTI Board of Directors. 2002 (December 12). Position Statement. Indianapolis, IN: Author.

"Inside the Rush Model: Leading an Organization of Leaders." 2003. Excellence in Nursing Administration 4(2). Retrieved November 25, 2003. <http://www.nursingsociety.org/publications/EXCEL_NA2_2Q.html>.
Kessenich, C.R., G.H. Guyatt and A. DiCenso. 1997. "Teaching Nursing Students Evidencebased Nursing." Nurse Educator 22(6): 25-29.

Kjonniksen, I., B.M. Andersen, V.G. Sondenaa and L. Segadal. 2002. "Preoperative Hair Removal - A Systematic Literature Review." AORN Journal 75(5): 928-38, 940.

Medves, J.M. and B.A. O’Brien. 1997. “Cleaning Solutions and Bacterial Colonization in Promoting Healing and Early Separation of the Umbilical Cord in Healthy Newborns." Canadian Journal of Public Health 88(6): 380-82.

Mitchell, A., K. Janzen, E. Pask and D. Southwell. 1995. "Assessment of Nursing Research Utilization Needs in Ontario Health Agencies." Canadian Journal of Nursing Administration 8(1): 77-91.

National Forum on Health (Canada). 1997. Canada Health Action: Building on the Legacy. Vol. 1. Ottawa: Author, 3-43.

Nilsson Kajermo, K., G. Nordstrom, A. Krusebrant and H. Bjorvell. 1998. "Barriers to and Facilitators of Research Utilization, as Perceived by a Group of Registered Nurses in Sweden." Journal of Advanced Nursing 27(4): 798-807.

Parahoo, K. 2000. "Barriers to, and Facilitators of, Research Utilization Among Nurses in Northern Ireland." Journal of Advanced Nursing 31: 89-98.

Rafael, A.R.F. 2000. “Evidence-based Practice: The Good, the Bad, the Ugly, Part 1." Registered Nurses Journal 12(4): 5-6, 9.

Titler, M.G. 2002. "Use of Research in Practice." In G. LoBiondo-Wood and J. Haber, eds., Nursing Research. (5th ed.). St. Louis: Mosby-Year Book.

UK Department of Health. 1999. "Making a Difference: Strengthening the Nursing, Midwifery and Health Visiting Contribution to Health and Healthcare." Retrieved November 7 , 2002. <http://www.doh.gov.uk/nurstrat.htm>.

Upton, D. 1999. "Attitudes Towards, and Knowledge of, Clinical Effectiveness in Nurses, Midwives, Practice Nurses and Health Visitors." Journal of Advanced Nursing 29: 885-93.

Writing Group for the Women's Health Initiative Investigators. 2002. "Risks and Benefits of Estrogen Plus Progestin in Healthy Postmenopausal Women: Principal Results from the Women's Health Initiative Randomized Controlled Trial." Journal of the American Medical Association 288: 321-33. 